\title{
Metacarpal Bone Digit 1
}

National Cancer Institute

\section{Source}

National Cancer Institute. Metacarpal Bone Digit 1. NCI Thesaurus. Code C52796.

The first and most medial of five miniature long bones located in the palm of the hand, which articulates proximally with the trapezium of the carpus at the carpometacarpal joint and distally with the thumb phalanx at the metacarpophalang eal joint. 